\title{
British Psychiatrists in Canada
}

\author{
C. M. Green, Clinical Director, Regional Psychiatric Centre (Prairies), Saskatoon, Saskatchewan
}

Canada has a long history of recruiting overseas doctors, including those specializing in psychiatry, for services in their country. Today there is a strong nucleus of British trained psychiatrists, practising in Canada, in spite of which multiple vacant psychiatric positions still exist and Canadian recruitment drives for British psychiatrists continue. Approximately four years ago, following reading an advertisement in the Journal concerning opportunities for psychiatrists in Canada, I and my family emigrated. Since this time I have been active myself in the recruitment of British psychiatrists for positions in Canada and my experience, as a British psychiatrist in Canada, may be useful for colleagues who are themselves contemplating such a move.

Socially and culturally British professionals appear to have little trouble settling in Canada. They find themselves well and easily accepted by Canadian people and enjoy a standard of living and comfort normally significantly higher than they had experienced in their home country. For psychiatrists financial remuneration is attractive, psychiatric salaries are generally in excess of $\$ 70,000$ a year and employee packages can be expected to hold adequate superannuation, sickness benefit schemes, etc. Employing authorities also tend to be generous in providing financial immigration assistance and in many cases an English family will be covered for all costs of moving themselves, their furniture and belongings, together with a period of hotel accommodation upon arrival in Canada. This is of course not the case if the family wishes at some time to return to England for employment. Movement to Canada is thus, in practice, often a one-way process, as the financial penalties of returning to reside in England tend towards being prohibitive.

The licensing situation for British physicians is somewhat complex. Each province has its own separate College of Physicians and Surgeons, who independently develop their own licensing requirements and conditions. The majority of provinces do not accept English licensing qualifications as being equivalent to either the Canadian LMCC or the USA's FLEX and will not issue a general license to practise for holders of British qualifications alone. Variations exist from province to province and it is necessary for the applicant to present his qualifications to the respective College of Physicians and Surgeons for necessary scrutiny and deliberation. However, provinces have, as a practical necessity for providing adequate medical services, made provision in their licensing regulations for the employment of non-Canadian trained physicians under 'special' or 'academic' licenses. In most provinces English trained physicians will have little difficulty in obtaining such a 'special license'. 'Special licenses' have a number of disadvantages in that they limit the field of medicine to which a holder is entitled to practise and also dictate in which facility a physician may work. Thus a psychiatrist who holds a 'special license' will not be allowed to practise privately, must generally limit his practice to psychiatry alone and is only liable to hold the 'special license' to practise as long as he works in the one particular institution designated by the province. Provinces tend to grant 'special licenses' for non-Canadian trained physicians to practise in areas where medical staffing is short and they have been unable to attract Canadian trained medical personnel.

In respect of psychiatric qualifications, the Canadian equivalent to the MRCPsych is the FRCP(Psych). I am led to understand that the Royal College of Psychiatrists in the United Kingdom accepts the Canadian FRCP(Psych) as an equivalent qualification. This is not the situation in reverse. Although both the Federal and Provincial authorities generally accept the MRCPsych as a suitable qualification for psychiatrists in their employ, there is an increasing movement that the FRCP(Psych) be considered mandatory for some senior and most academic positions.

It is thus entirely possible for psychiatrists to practise in Canada, holding only British general medical and psychiatric qualifications and indeed a number of senior positions are held by such qualified British psychiatrists. There are, however, as outlined above, a number of disadvantages to not obtaining Canadian qualifications and British psychiatrists contemplating immigration to Canada should seriously consider undertaking the examinations for the LMCC and FRCP(Psych). In particular, British qualified psychiatrists are liable to be strongly encouraged, sometimes expected, to eventually obtain their FRCP(Psych) by their employing authority. In order to sit the examination for the FRCP(Psych) the applicant must first submit a comprehensive curriculum vitae of his psychiatric training, together with supportive documentation from his past psychiatric duties and supervisors to the Royal College of Physicians and Surgeons in Ottawa. The Royal College of Physicians and Surgeons will then determine if the applicant's training is considered suitable for him to be allowed to sit the FRCP(Psych) examination. In the event that the training is considered inadequate, a further period of training at an approved Canadian facility will be required before the examination can be taken. It is thus possible that a British trained psychiatrist may be required to undergo further psychiatric residency training in Canada before he can sit the FRCP(Psych) and for this reason it may be sensible for British psychiatrists considering employment in Canada to have their training assessed by the Canadian Royal College of Physicians and Surgeons prior to leaving the United Kingdom.

There is often considerable room for negotiations over accepting a psychiatric position in Canada, a practice the 
British psychiatrist is not likely to be familiar with. Licensing requirements, being governed by provincial law, are generally not negotiable, salaries, removal expenses, holidays, etc. often are. The British psychiatrist should be aware that he is offering his services in a more open, free enterprise, situation than is the case in his home country and accordingly should examine in detail what is being offered to him, as well as what alternative opportunities may be available in other parts of the country.

In concluding, it is my experience that the great majority of British psychiatrists in Canada are well content with their new country and lead professionally rewarding lives. The practice of psychiatry in Canada appears to be more heavily influenced by British rather than American influences and indeed many senior positions are held by British qualified psychiatrists. Factors to be considered by a British psychiatrist before emigrating are multiple and should certainly include the implications of the type of license to practice that is to be granted and the feasibility of eventually taking Canadian qualifications. It is often possible to negotiate a trip to Canada to view a position and, in my opinion, this is by far the best and safest way for a potential immigrant psychiatrist to fully explore all the intricacies of a potential post.

The views and opinions expressed in this article are those of the author and should not be considered in any way representative of any official body or organization.

\section{What Are Rates? \\ Some notes about the application of and the difference between rates in describing health service data}

\section{E. L. KonTY and S. J. JonEs. Nottingham University Department of Psychiatry, Queens Medical Centre, Nottingham}

In recent years there has been a move away from the purely literary to the numerically descriptive medical publications. This is largely attributable to a change in emphasis and direction in the medical sciences as practitioners become more 'mathematically aware'. Sample populations are often described in terms of numbers, ratios, percentages or rates. All of these descriptors have merit in supporting the expression of methods and results in clinical trials, research and epidemiology. The application of rates can be most useful, particularly as results are not always considered in terms of simple numerical counts, but are often related to an underlying population.

Most clinicians today have developed numerate skills and have a reasonable appreciation of the meaning and value of rates-related statistics. But there still exists difficulty in understanding the reasons for applying particular types of rates in given circumstances. Why, for example, if one has knowledge of the age distribution in a patient sample. are total population rates still used? Are there sometimes advantages in not using age-specific rates?

The following paragraphs explain the difference between total and specific rates and illustrate their uses and limitations by means of examples taken from locally available admission information.

\section{Numbers and percentages}

The presentation of data in simple numerical form often gives a good indication of service utilization and is useful in expressing simple workload statistics. The calculation of percentages gives some measure of dispersion and often has more impact than simply quoting numbers. For example (Table I), the number and percentages of admissions for Nottingham in 1981 were as follows:
TABLE I

Admissions for 1981: numbers and percentages

\begin{tabular}{ccc}
\hline Age & Number & \% of all admissions \\
\hline $15-64$ & 1114 & 70 \\
$\frac{65 \&+}{15 \&+}$ & $\frac{470}{1584}$ & $\frac{30}{100}$ \\
\hline
\end{tabular}

These figures indicate that 30 per cent of admissions were for those patients aged 65 and over. Such a statement clearly has more impact than saying ' 470 patients out of a total of 1,584 were aged 65 or more on admission'.

To describe local service or workload activities, it is often sufficient to quote actual numbers rather than rates. A simple count of people or events, however, has parochial value and as no account is taken of the background population, it has several limitations. For example: the fact that Nottingham had 1,584 admissions and Southampton had 1,414 , during the same period of time, indicates that Nottingham's admission workload is slightly higher. However, the underlying total populations are quite different: Nottingham's area had 380,000 people, while Southampton's area included 165,000 people. Such knowledge immediately raises the question as to which sections of the two populations are most notably affecting these admission figures.

The next example illustrates the use of rates, and shows how rates by total population differ from age and sex specific rates.

\section{Total population rates}

These are often referred to as crude rates. Most simply, 